\title{
Continuous supply chain collaboration: Road to achieve operational excellence
}

\author{
N. Senthil Kumar ${ }^{\mathrm{a}^{*}}$ and P. Subburethina Bharathi ${ }^{\mathrm{b}}$ \\ ${ }^{a}$ Department of Management Studies, Anna University, Chennai - 600 025, Tamilnadu, India. \\ ${ }^{b}$ Hallmark Business School, Tiruchirappalli - 620 102, Tamilnadu, India.

\begin{tabular}{|c|c|}
\hline$\overline{\text { A R T I C LE I N F O }}$ & AB S TRACT \\
\hline $\begin{array}{l}\text { Article history: } \\
\text { Received October } 12010 \\
\text { Received in revised form } \\
14 \text { December } 2010 \\
\text { Accepted } 15 \text { December } 2010 \\
\text { Available online } \\
16 \text { December } 2010 \\
\text { Keywords: } \\
\text { Continuous supply chain } \\
\text { collaboration (CSCC) } \\
\text { Supply chain management } \\
\text { Continuous improvement } \\
\text { Operational excellence } \\
\text { Supply Chain Management }\end{array}$ & $\begin{array}{l}\text { Supply chain management (SCM) is becoming critical as firms recognize that competition is } \\
\text { shifting from company versus company to supply chain versus supply chain. In the present } \\
\text { competitive scenario, the fierce competition has driven most companies to seek for means of } \\
\text { enhancing performance beyond their four wall boundaries. The firm's ability in collaborating } \\
\text { with its upstream and downstream partners determines its success in attaining better } \\
\text { performance with supply chain collaboration; a firm is able to serve fragmented markets in } \\
\text { which end customers require more product varieties and availability with shorter product life } \\
\text { cycle and, at the same time, lower supply chain costs. This paper introduces the framework of } \\
\text { continuous supply chain collaboration (CSCC), which extends the traditional frame of reference } \\
\text { in strategic sourcing from a supplier centric to a supply-chain-scope as continuous } \\
\text { improvement efforts to enhance the customer satisfaction. CSCC practices are rather } \\
\text { exceptional, yet CSCC is believed to be the single most comprehensive framework for attaining } \\
\text { operational excellence. }\end{array}$ \\
\hline
\end{tabular}

\section{Introduction}

Supply chain management (SCM) was evolved from a traditional focus on purchasing and logistics' practices between 60's and mid 90's, to a broader, more integrated emphasis on value creation in the new millennium. In the present scenario global companies increasingly view supply chain excellence as more than just a source of cost reduction, rather, to a source of competitive advantage. Supply chain management is expressed as a strategy of choice for improving competitiveness (Rich \& Hines, 1997; Quinn, 1997). Effective collaboration with entity (cross-functional) and chain of entities (crossenterprise) is essential to achieve goals, individually, collectively and continuously. The idea that strategic supply chain alliances are an important frame work for value creation. This evidence is supported by studies suggesting that, on average, alliances do create economic value (Anand \& Khanna, 2000). The supply chain council (2008) has evolved the supply chain operational reference (SCOR) model for the purpose of proactively modeling and assessing the relationships between the sequential stages of a supply chain. Collaboration is a recognized term which could explain many 
features. Based on Min et al. (2005), collaboration must be defined as a firm's culture of working together with other firms towards a common set of goals that bring mutual benefits to a partnering relationship. According to Bowman (2004), the best supply-chain performers are deeply involved in relationships that call for tight links among partners. It is an environment where information flows freely in both directions, upstream to suppliers, or downstream to customers. The situation where manufacturers, distributors and retailers respond quickly to changing business conditions and customer service is paramount. This research framework suggests that most supply chain management initiatives can be positioned in a conceptual space made of four levels of supply chain integration.

\section{Evolution of Supply Chain Management}

A SCM is a large network of suppliers, factories, warehouses, distribution centers and retailers, through which raw materials are sourced processed and delivered to the customer. Being a complex network of several entities, the success of any supply chain management system depends on how well these system entities are managed and contributed. SCM now is a dynamic entity that is constantly changing in response to changes in technology, competitive actions, and customer demands. The "new" supply chain is characterized by three major traits: (a) strategic; (b) dynamic; and, (c) customer driven. It is strategic as it enhances the ability of a firm to develop and maintain strategic advantages in a competitive market. It is dynamic in that it is constantly evolving as a result of strategic changes in the firm, competitive actions, changes in technology, and shifts in customer needs. It is customer-driven as supply chains must focus on value propositions that are highly attractive to customers. The supply network that serves these customers must be optimized and react to supply uncertainties and demand variability.

\subsection{Supply Chain Management Integration}

Increasingly managers, researchers, and educators recognize the importance of SCM as both a strategic and tactical weapon. However, the practice of supply chain management is ever changing. Originally, the supply chain was viewed as an entity that was primarily concerned with the upstream and downstream management. By the mid 1990s, there was a change in orientation and the focus was shifted from the upstream to the entire supply chain. From the beginning of the new century, there has been a shift in focus from supply chain management to strategic supply chain management. As this transition occurs, there is a strong need for researchers, managers, and educators to reassess the current and future stages of supply chain management to reach the goals of identifying, presenting, and implementing a new set of agendas. These agendas are targeted at directing, motivating, and facilitating research, knowledge dissemination and management/practice in this area.

\subsection{Supply chain partnering}

Fynes and Voss (2005) stressed that adopting supply chain orientation requires establishing relationships among the channel partners. The successful partnering is important for companies to improve their business performance, as confirmed by Wong (2002) in his study on "Sustaining company performance through partnering with suppliers". He identified that one of the concept of success in company performance is that they work closely with the suppliers. The empirical studies reveals that in the domain of SCM relationships have transformed to the relationship perspective which stresses interdependence, connectedness and intimate relationships from the transaction cost economizing dyadic perspective where business relationships are seen as isolated phenomena (Sako et al., 1994; Lamming, 1993, Fynes \& Voss, 2005). Table 1 summarizes the history of SCM. 


\section{Table 1}

The historical trend on SCM literature

\section{Conceptual approaches of SCM}

Authors, years

Integration of various functional areas of an organization to improve the flow of goods from the direct strategic suppliers up to the end user, along the Houlihan, 1987 production and distribution chain

A management philosophy that reflects a systemic view of SC (by viewing the chain as a single entity) based on partnership concept that involves the joint efforts of several companies directed to total goods flow management, Ellram \& Cooper, 1990 from supplier to final customer

\section{Management of relationships between corporate functions and companies}

"Integration of key business processes from end user through original suppliers that provides products, services and information that add value for customers and other stakeholders”

Global supply chain forum (GSCF), cited in Lambert et al., 1998

A set of approaches used to efficiently integrate suppliers, manufacturers, warehouses, distribution and sales centers, implying the production and distribution of goods in adequate quantities, at the right place and the right time, in order to minimize overall system cost while satisfying the requested

Simchi-Levi et al., 2000 level of demand and customer service

To improve the long term performance of the compaines and the supply chain as a whole systemic, strategic coordination of the traditional business functions and the tactics across these business functions within a particular company and across businesses within the supply chain is essential.

The proactive management of bidirectional coordination and movement of goods, services, information and funds, from raw material to final user

Trent, 2004

Since SC is a network of companies, or independent business units, from original supplier to end customers, management of this network is a complex task having the goal to implement cross-functional business processes and Lambert et al., 2005 integrate them with other key members of the chain

"Alliances with key partners, and information technology that allows supply chain partners to share accurate information on a timely basis are the building blocks of efficient and responsive supply chain operations. Upon this foundation, the introduction of lean manufacturing and lean logistics processes, together with the integration of key business processes up and down the supply chain create SCM”.

\subsection{Supply Chain Collaboration}

Extensive research literature on supply chain collaboration (SCC) is very wide-ranging in both business and academia, but not always on objective. The path to susscessful collaboration is to concentrate on the ways that entities in supply chains work together. Collaboration proves to be important since, as Cooper et al. (1997) formulate, sub-optimization occurs when each organization in the supply chain attempts to optimize its own results rather than integrating its goals and activities with other organizations to optimize the results of the whole chain. All entities in the supply chain 
must work togeather for successfully formulating the fitting strategy. Collaboration in business can be found both in inter and intra organization and ranges from the simplicity of a partnership to the complexity of a multinational corporation. According to Barratt (2004), there are a variety of forms of potential supply chain collaboration, which can be divided into two main categories, vertical and horizontal collaboration. Furthermore, Soosay et al. (2006) states the third form of collaboration namely 'lateral collaboration', where it combines the benefits and sharing capabilities of both vertical and horizontal integration. Blanchard (2007) observes that collaboration is cited as the single most pressing need; but how to achieve it is not well understood. Hence, there is a gap to strengthen the collaboration inside the SCM network. This research paper explores a new framework continuous supply chain collaboration (CSCC) dealt in the following sections.

The objective of this paper is to evolve the next level in the integration of the SCM elements, beyond partnership and collaboration, to attain operational excellences. Next section elaborates several stages of integration in the global SCM arena.

\title{
3. Global trends in SCM
}

In order to highlight the path towards the current stage of development in the field of SCM in the global scenario, we summarize different trends of SCM in Table 2.

\section{Table 2}

The historical trends on SCM

\author{
Global SCM trends 2010
}

\begin{abstract}
Liberalization, privatization and globalization (LPG) is picking up the pace, which leads to large Trend 1 structural shifts for dynamic global supply chain organizations.

Cost cutting and enhancing the accessability to local markets continue to drive globalization. Inspite of average cost reductions many companies have difficulty realizing savings in management costs.

Trend 2
\end{abstract}

Global corporates are converging on India and China as the major target regions for globalization.

Trend 3

When supply chain initiatives are expanded across the globe supply chain delivery and security are the most critical concerns.

Trend 4

The major barriers in globalization of initiatives are the supply chain flexibility and inadequate internal competency.

Future globalization strategies will revolve around environment of sustainability and complying on regulatory compliances, customer satisfaction and demand.

The need for greater supply chain flexibility will go beyond product quality and customer service as the vital initiative for improving supply chain strategy.

The top management agenda across industries and geographic regions is converging on improving supply chain flexibility and performance through continuous improvement.

\subsection{The tiger and the dragons of supply chain}

Over the past few years, India (tiger) has launched its breakout to connect to the world as a rising economic superpower of the future. The transformation is already evident. Foreign direct investment has risen to over US\$14bn and economic growth for the fiscal year of 2010 is predicted to be $9.4 \%$, among the highest in the world. While the current logistics infrastructure remains a key barrier to efficiency, the rise of the consumer is placing enormous pressure on the government and private markets to move faster to meet demands, and the economic benefits that will result. Within the next five years, organized retail will account for more than $20 \%$ of all consumer purchases, resulting in 
more than \$120bn in new consumer spending. In order to reach its full potential, India must launch a bold SCM strategy to enhance the customer satisfaction. The rise of India as a new economic powerhouse will further propel these changes, and at the same time introduce new models in the supply chain by combining innovative technologies and virtual networks to meet the country's growing consumer demand. If properly leveraged, the complex challenges presented by the Indian market today can become unique opportunities for the future. With the world's largest youth population, India is uniquely positioned to convert investment in SCM infrastructure into dynamic economic growth. While China's competitive advantage has been manufacturing, India's advantage is in competitive indigenous technology. In a sense, China has been building highways, while India has been building virtual highways. India should now utilize its unique technological advantage to create entirely new models of supply chain networks to break through barriers and ensure sustained economic growth. The government has recently committed new investment in ports, airports, and highways; but Indian also needs new strategies to rapidly evolve to meet rising consumer expectations and satisfying them. A number of companies in India are creating new business models by intentionally focusing global best practices with unique knowledge of the local market. The next section explains the development of the CSCC framework to enhance the customer satisfaction through the four levels.

\subsection{Climbing the ladder from SCM to CSCC}

Fig. 1 shows the CSCC framework which is developed in this paper. The CSCC framework consists of the flowing four levels:

Level I : SCM

Level II : SCM Partnering

Level III: SCM Collaboration

Level IV: CSCC
From 1960s to 1980s

From 1980s to 2005

From 1990s to 2010

2010 and beyond

\subsubsection{Level: I Supply Chain Management}

The supply chain is a complex network of organizations, which includes enterprises devoted to manufacturing, purchasing, distribution, marketing, etc, and it can be essentially organized in two different ways. A central partner normally controls the SCM which is dominant respect to the other components of the supply chain in taking the necessary actions. Supply chain management consists of planning and management of all activities involved in sourcing and procurement, conversion, and all logistics management activities. SCM also includes integration with channel partners, which can be suppliers, intermediaries, third party service providers, and customers. In nutshell, supply chain management integrates supply and demand management within and across companies.

\subsubsection{Level: II Supply chain partnering}

Supply-chain partnering has emerged as an important trend at the end of the last century. The effective management of supply chains is said to be characterized by developing close, long-term working relationships with a limited number of supply chain partners. The supply chain partnering (SCP) ensures a systematic process of developing, implementing and continuously improving corporate relationships across the supply chain. SCP is an internal program aimed at improving overall effectiveness of SCM. The SCP focus is shifted from increasing the internal efficiency of organizations to the methods of reducing waste and adding value across the entire supply chain. Unless there is a strong foundation of effective relationships, any effort to manage the flow of materials and information across the supply chain are likely to fail. Building a partnership among the firms is one way to find and maintain competitive advantage. 


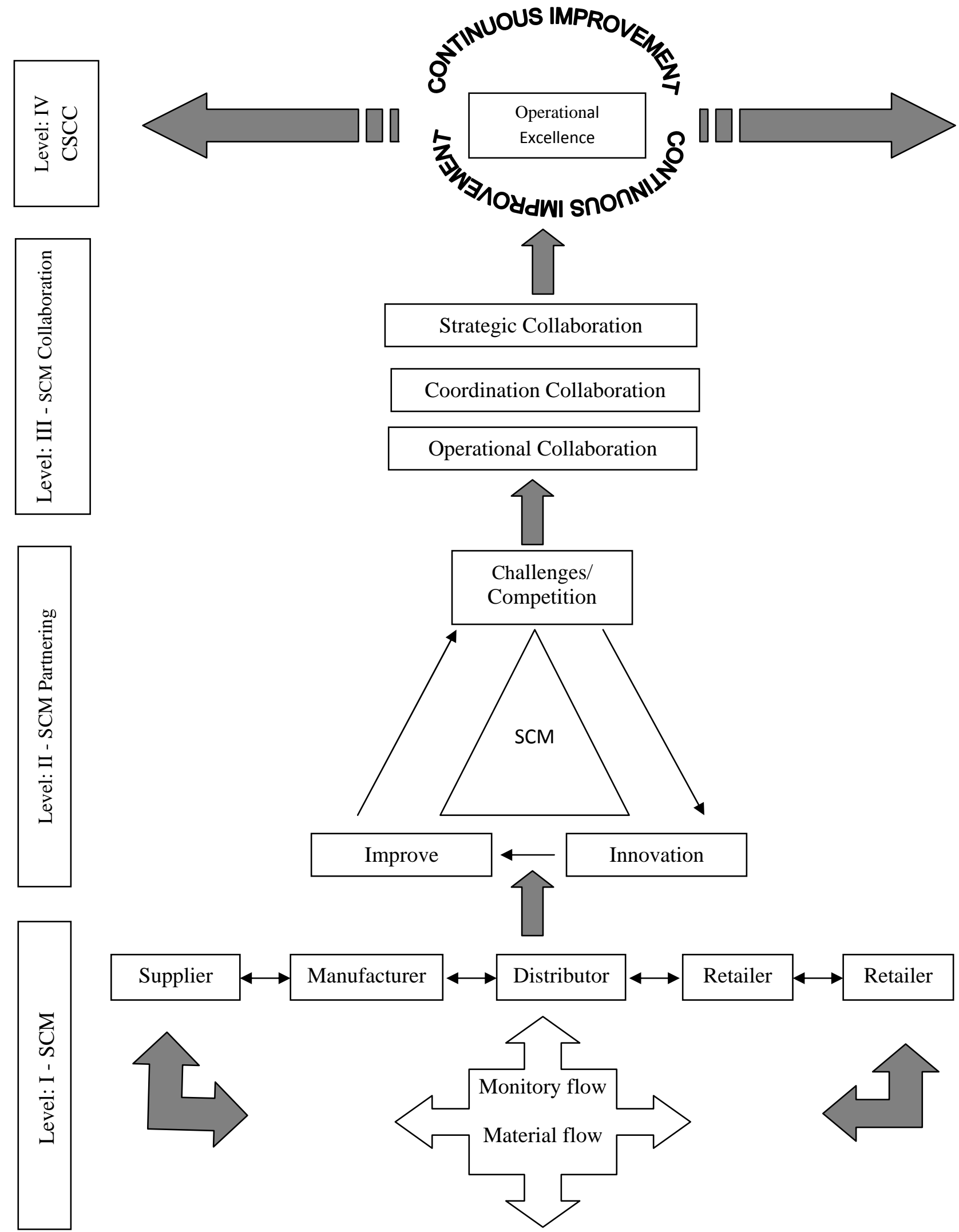

Fig. 1. CSCC frame work showing the four levels of integration

A blend of local and global excellence in operational initiatives provides the best means to make specific improvements and ensures a common understanding among supply chain partners. Trust is considered to be a critical factor nurturing commitment among supply chain partners. The presence of mutual trust improves the chance of successful supply chain performance. A deficient in trust among 
supply chain partners results in inefficient and ineffective performance as the transaction costs climbs up (Kwon, 2004).

\subsubsection{Level: III Supply chain collaboration}

As a supply chain perspective entails looking beyond the supply chain partners, it is important to have a trusting relationship among them, where each party has mutual confidence with other members' capabilities and actions which leads to the collaboration in SCM. The levels of collaboration among business partners will vary depending upon the organizations perspective role in the supply chain. SCM collaboration was evolved in three stages as follows,

Stage I: Operational collaboration: deploy activities more efficiently within the existing logistic structure, Partners collaborate at an operational level in a short term horizon.

Stage II: Coordination collaboration: achieve savings by coordination amnog parties, Partners exchange information and planning together with a midterm horizon.

Stage III: Strategic collaboration: accomplish structural savings as a result of restructuring of the shared logistic structure.

Supply chain collaboration provides the efficient exchange of planning information among trading partners to ensure streamlined and optimized management of the flow of parts and materials into the plant. Types of information exchanged include material plans, inventory and capacity availability, performance scorecards, and key performance indicators. The real source of sustainable competitive advantage will rather be the ability to innovate on a continual basis. The main benefits of supply chain collaboration are summarized in two items of lowered inventory costs and increased customer responsiveness. Collaborative product introduction requires extremely strong relationships with suppliers to successfully execute on product design, sourcing, supplier selection, and production ramp up. To collaborate on demand planning successfully, business partners need to share and modify each other's demand plans and forecast electronically. Once demand plans and forecasts are in place, replenishment plans are designed to assume adequate product availability would be jointly developed.

\subsubsection{Level IV: CSCC}

Companies determined for operational excellence at all levels must have a model for continuous improvement. Operational excellence in the supply chain is not an option anymore since it becomes mandatory in the increasingly competitive global game. Achieving operational excellence requires continuous improvement in all facets of the supply chain operation. Continuous improvement in supply chain is definitely a difficult task, but not an impossible task to attain. Most effective continuous improvement programs should comprehensively analyze performance, identify areas of weakness, and rapidly lead to the necessary improvements. Continuous improvement in SCM has been widely adopted and regarded as providing an important component of increased company competitiveness. CSCC stresses that lean, Six Sigma, theory of constraints, Benchmarking, and other continuous improvement programs are only tools. It is important to choose the right tool for the right problem. The steps to be adopted in the continuous improvement process in the SCM integration are:

1. Establish the supply chain performance baseline using benchmarking and best practices data

2. Perform a gap analysis of current processes with the identified best practices

3. identify the improvement opportunities that will significantly impact performance by drilling down the key supply chain processes

4. Develop goals, objectives and a project plan for each improvement opportunity

5. Channalize resources to make recommendations and implement justified improvements

\section{Conclusion}

The driving forces of effective CSCC are partnering and collaboration. CSCC demands collaboration among all participants in the Supply chain, regardless of their size, function, or relative position. The CSCC framework insists on creating a shared vision for companies, suppliers, and customers can 
partner to achieve continuous improvement in continuous supply chain performance. The customersupplier integration calls for commitment and trust over an extended time period which includes sharing of information, risks and rewards. CSCC is an unexplored sea of opportunity in the present competitive scenario. CSCC framework will develop greater efficiency in attaining operational excellence and customer satisfaction.

\section{Reference}

Anand, B. N., \& Khanna, T. (2000). Do firms learn to create value? The case of alliances. Strategic Management Journal, 21, 295-315.

Barrett, M. (2004). Understanding the meaning of collaboration in the supply chain. Supply Chain Management: An International Journal, 9(1), 30-42.

Blanchard, D. (2007). Supply Chain Management Best Practices. John Wiley \& Sons, New Jersey.

Bowman, R. J. (2004). More than a buzzword: Collaboration is the key to high-performing supply chains. Global Logistics \& Supply Chain Strategies, 8(11), 52- 56.

Cooper, M. C., Lambert, D. M., \& Pagh, J. D. (1997). Supply chain management: more than a new name for logistics. International Journal of Logistics Management, 8(2), 1-14.

Ellram, L. M., \& Cooper M. C. (1990). Supply chain management, partnerships, and the shipper-third-party relationship. The International Journal of Logistics Management, 1(2), 1-10.

Ellram, L. M., \& Cooper, M. C. (1990). The relationship between supply chain management and keiretsu. The International Journal of Logistics Management, 4(1), 1-12.

Fynes, B. J., de Búrca S., \& Voss C. A. (2005). Supply chain relationship quality, the competitive environment, and performance. International Journal of Production Research, 43(16), 3303-3320.

Houlihan, J. B. (1987). International supply chain management. International Journal of Physical Distribution \& Materials Management, 17(2), 51-66.

Kwon, I.-W. G. \& Suh, T. (2004). Factors affecting the level of trust and commitment in supply chain relationships. Journal of Supply Chain Management, 40: 4-14.

Lambert, D. M., Garcia-Dastugue, S., \& Croxton, K. L. (2005). An evaluation of process-oriented supply chain management frameworks. Journal of Business Logistics; 26(1), 25-57.

Lambert, D. M., Cooper, M. C., \& Pagh, J. D. (1998). Supply chain management: Implementation issues and research opportunities. The International Journal of Logistics Management, 9(2), 1-19.

Lamming, R. (2003). Beyond partnership strategies for innovation and Lean supply, Prentice Hall.

Mentzer, J.T., DeWitt, W., Keebler, J.S., Min, S., Nix, N.W., Smith, C.D. \& Zacharia, Z.G. (2001). Defining supply chain management. Journal of Business Logistics, 22(2), 1-25.

Min, S., Roath, A. S., Daugherty, P. J. Genchev, S. E., Chen, H., Arndt, A. D. \& Richey, R. G. (2005). Supply chain collaboration: what's happening. The International Journal of Logistics Management, 16(2), 237256.

Quinn, F. J. (1997). Team up for supply-chain success. Logistics Management, 36, 39-41.

Rich, N., \& Hines, P. (1997). Supply-chain management and time-based competition: The role of the supplier association. International Journal of Physical Distribution \& Logistics Management, 27(3/4), 210-225.

Russell, S. H. (2007). Supply Chain Management: More Than Integrated Logistics, Air Force Journal of Logistics, 31(2), 55-63.

Sako, M., Lamming, R., \& Helper, S. R. (1994). Supplier relations in UK car industry: Good New and Bad News. European Journal of Purchasing and Supply Management, 1(4), 237-248.

Simchi-Levi, D., Kaminsky, P., \& Simchi-Levi, E. (2000). Designing and Managing the Supply Chain: Concepts, Strategies, and Case Studies, Irwin McGraw-Hill, USA.

Soosay, C. A., Hyland, P. W, \& Ferrer, M. (2006). Supply chain collaboration: capabilities for continuous innovation. Supply Chain Management: An International Journal, 13(2), 160-169.

Supply-Chain Council (2008). Supply chain operations reference model version 9.0. Supply- Chain Council, Pittsburgh, USA.

Trent, R. J.(2004). What everyone needs to know about SCM. Supply Chain Management,Review,8(2), 52.

Wong, A. (2002). Sustaining company performance through partnering with suppliers. International Journal of Quality \& Reliability Management, 19(5), 567-580. 